\title{
Section: Medicine
}

\section{Original Article}

ISSN (0): 2347-3398; ISSN (P): 2277-7253

\section{Mortality in Swine Flu: Descriptive Study}

\author{
Srinivasa Jutur ${ }^{1}$, Krishna Kumar Naik $\mathbf{T}^{1}$ \\ ${ }^{1}$ Assistant Professor, Department of General Medicine, KIMS, Koppal, Karnataka.
}

\section{Abstract}

Background: Swine influenza is an infection caused by any one of several types of swine influenza viruses. Swine influenza virus (SIV) or swine-origin influenza virus (S-OIV) is any strain of the influenza family of viruses that is endemic in pigs. As of 2009, the known SIV strains include influenza $\mathrm{C}$ and the subtypes of influenza A known as H1N1, H1N2, H2N1, H3N1, H3N2, and H2N3. Subjects and Methods: The patients with clinical features of Influenza like illness were enrolled. A complete clinical examination was carried out and relevant investigations done and documented in the proforma. Results: Most common symptoms at presentation were cough (93\%), fever $(92 \%)$ followed by sore throat (76\%). Breathlessness was found in $28.76 \%$ of patients at presentation of which nearly $3 / 4$ th died. $72 \%$ patient died of ARDS and out of which 79\% were female. Conclusion: Most common cause of death was acute respiratory distress syndrome (72\%) followed by secondary infection with septicemia.

Keywords: Swine influenza virus, Mortality, Cough.

Corresponding Author: Dr. Krishna Kumar Naik T, Assistant Professor, Department of General Medicine, KIMS, Koppal, Karnataka.

Received: April 2019

Accepted: April 2019

Introduction

SWINE FLU - the term has created panic in the minds of people across the world. The disease caused by $\mathrm{H} 1 \mathrm{~N} 1$ virus has spread rapidly \& difficult to control with no definitive management. Rajasthan has also been severely affected \& jaipur being the nodal centre for the state.

One of several types of swine influenza viruses. It belongs to influenza family of viruses is endemic in pigs. In 2009, SIV strains are influenza $\mathrm{c}$ and the subtypes known as H1N1, H1H2, H2N1, H3N1, H3N2, and H2N3. ${ }^{[1,2]}$

Swine influenza is an infection caused by any one of several types of swine influenza viruses. Swine influenza virus (SIV) or swine-origin influenza virus (S-OIV) is any strain of the influenza family of viruses that is endemic in pigs. ${ }^{[2]}$ As of 2009, the known SIV strains include influenza C and the subtypes of influenza A known as H1N1, H1N2, H2N1, $\mathrm{H} 3 \mathrm{~N} 1, \mathrm{H} 3 \mathrm{~N} 2$, and H2N3.

IN 2009 swine flu was 1st noticed in human in mexico, where particular virus strain was a mixture from 3 types of strains. Six genes were very similar to the H1N2 influenza virus found in pigs. ${ }^{[3]}$

Worldwide Swine influenza virus is common in pig populations. Pigs to humans transmission is not common and does not lead to human flu, resulting only in the production of antibodies. If transmitted does cause human flu, it is called zoonotic swine flu. Exposure to pigs are at increased risk of swine flu infection. ${ }^{[4]}$

Swine-flu has incubation period of 2 to 7 days and transmitted by droplets or fomites. Most present with mild symptoms of fever, cough, sore throat, headache, joint pain and myalgia. Gastrointestinal symptoms is more common Swine flu is a highly contagious disease of pigs caused by several swine influenza viruses, the present pandemic caused by H1N1 virus. The mortality is usually low (1-4\%) though morbidity tends to be high.

Agent H1N1 virus spreads through droplet infection \& fomites with an incubation period of 1-7 days. Humidity favors transmission of the virus. Young adults are the most common age group affected with females having a higher mortality rate..$^{[5]}$

Among intubated patients, viral RNA has been detected at higher levels and for longer periods in lower respiratory tract than in the upper respiratory tract. In contrast to the damage caused by the virus infection to the tracheobronchial epithelium in uncomplicated influenza, damage to the alveolar epithelium has severe consequences for the gas exchange function of the respiratory tract. It allows fluid from the alveolar capillaries to flood lumina, causing severe and in some cases fatal respiratory dysfunction. ${ }^{[6]}$

Determinants of progression of a predominantly upper respiratory tract infection to fatal pulmonary disease are a number of different factors such as age, immune and underlying health status, preexisting immunity to viral antigens and pharyngeal bacterial flora. ${ }^{[7,8]}$

In patients with uncomplicated influenza, bronchoscopy typically reveals diffuse inflammation and edema of the larynx, trachea, and bronchi, and biopsy may show cellular infiltration with lymphocytes and histiocytes and desquamation of the ciliated columnar epithelium. In patients with severe influenza infections that progress to primary viral pneumonia, the involvement of the respiratory 
tree is extensive, with necrotizing tracheobronchitis, ulceration and sloughing of the bronchial mucosa, hyperemic alveolar capillaries with intra-alveolar hemorrhage, infiltration of alveolar spaces with fluid, fibrin, and cellular exudates, and lining of the alveoli with acellular hyaline membranes. Autopsies from patients with primary influenza pneumonia confirmed bilateral severe hemorrhagic pneumonitis with interstitial inflammation, diffuse alveolar damage, and heavy viral loads observed in the periphery of the lungs.

Prominent hemophagocytosis in spleen, lymph nodes and bone marrow have been noted. Brain shows multiple focal hemorrhage with diffuse secondary ischemic injury.

The patterns of innate and adaptive immune responses in patients with $2009 \mathrm{H} 1 \mathrm{~N} 1$ virus infection are incompletely characterized. Seasonal and pandemic 2009 H1N1 viruses induce similar proinflammatory mediator responses in human cells in vitro but do not activate effective innate antiviral responses in human dendritic cells and macrophages. Increased plasma levels of interleukin-15 interleukin-12p70, interleukin-8, and especially interleukin6 may be markers of critical illness. ${ }^{[9]}$

Immunity to influenza is long lived and subtype specific. Antibodies against HA and NA are important in immunity to influenza, whereas antibodies against the other virus encoded proteins are not protective. Resistance to initiation of infection is related to antibody against the HA, whereas decreased severity of disease and decreased ability to transmit virus to contacts are related to antibody against the NA. Antibodies against the ribonucleoprotien are typespecific and are useful in typing viral isolates (as influenza A or B).

Infection with the $2009 \mathrm{H} 1 \mathrm{~N} 1$ virus causes a broad spectrum of clinical syndromes, ranging from afebrile upper respiratory illness to fulminant viral pneumonia.

Mild illness is characterized by influenza like illness with fever, cough, sore throat rhinorrhea, dyspnoea, malaise and myalgia. Systemic symptoms like nausea, vomiting and diarrhea.

Severe illness is characterized by features of chest pain, hemoptysis or purulent sputum, prolonged or recurrent fever, altered mental status, manifestation of dehydration and reappearance of lower respiratory tract symptoms. The principal clinical syndrome leading to hospitalization and intensive care is diffuse viral pneumonitis associated with severe hypoxemia, ARDS, and sometimes shock and renal failure. ${ }^{[10]}$

\section{Subjects and Methods}

\section{Source of data}

This was a prospective study, which included patients with influenza like illness, who got admitted to attached hospitals of. Medical college

\section{Method of collection of Data}

The patients with clinical features of Influenza like illness were enrolled. A complete clinical examination was carried out and relevant investigations done and documented in the proforma.

\section{Inclusion criteria}

Proved cases of influenza A H1N1 and negative cases, where no other specific diagnoses were clinched.

\section{Exclusion criteria}

All other Influenza like illness patients where specific diagnosis other than influenza A H1N1 was clinched were excluded from the study group.

\section{Investigations}

Complete Hemogram

CBC profile of every patient was obtained from Automated Hematology

\section{Results}

\section{PERCENTAGE DISTRIBUTION OF SYMPTOMS}

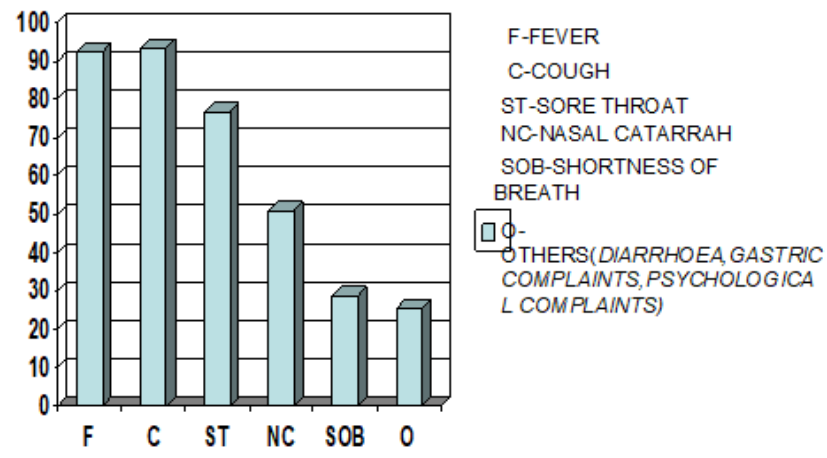

Figure 1: Symptoms

Table 1: Mortality

MORTALITY WITH RESPECT TO AGE

\begin{tabular}{|c|c|c|c|}
\hline AGE IN YEARS & FEMALE & MALE & TOTAL \\
\hline$<20$ & 3 & 3 & 6 \\
\hline $20-25$ & 3 & -- & 3 \\
\hline $25-30$ & 6 & -- & 6 \\
\hline $30-35$ & 6 & 3 & 9 \\
\hline $35-40$ & 7 & 3 & 10 \\
\hline $40-45$ & 6 & -- & 6 \\
\hline$>45$ & 3 & -- & 3 \\
\hline & 34 & 9 & 43 \\
\hline
\end{tabular}

$72.09 \%(31 / 43)$ died of ARDS $79.06 \%(34 / 43)$ were females

\section{Discussion}

Swine flu was first recognized in the state of Veracruz, in 2009 .In 2009 swine flu pandemic is a global outbreak of novel H1N1 strain invilving more than 170 countries spread 
over all the continents nearly affecting more than 1 lakh population. ${ }^{[4]}$

Pune in India first reported the case and rapidly spearding involving more than 2500 confirmed cases with mor than 30 deaths.

Nearly half of the swine flu positive patients were less than 15 years of age. Higher communicability of the virus among children \& faster spread in places like schools through fomites being probable reasons.

According to one study in Indian by p sriram et al Children and Young adults were commonly affected and nearly $40 \%$ of those affected have been children less than 14 yrs which goes hands with out study. ${ }^{[3]}$

$75 \%$ of the patients who tested positive were from urban areas with low socioeconomic status. Poor accessibility \& awareness of the disease in rural areas combined with high cost of testing may be the reasons for the above observations.

Interestingly males were affected more $(62.65 \%)$ than females. However the mortality was higher in females (79.06\%) for reasons unknown.

According xi-ling wang et al, men showed higher excess hospitalization rates than women, with MFRs larger than 1.0 in most age-sex-disease. ${ }^{[6]}$

Most common symptoms at presentation were cough (93\%), fever $(92 \%)$ followed by sore throat $(76 \%)$. Breathlessness was found in $28.76 \%$ of patients at presentation of which nearly $3 / 4$ th died.

$72 \%$ patient died of ARDS and out of which $79 \%$ were female.

\section{Conclusion}

Most common cause of death was acute respiratory distress syndrome $(72 \%)$ followed by secondary infection with septicemia.

\section{References}

1. Mu YP, Zhang ZY, Chen XR, Xi XH, Lu YF, Tang YW et al., Clinical features treatments and prognosis of the initial cases of pandemic influenza H1N1 2009 virus infection in Shanghai China. Q J Med 2010; 103:311-7.

2. Jain S, Kamimoto L, Bramley AM, Schmitz AM, Benoit SR, Louie J et al. Hospitalized patients with $2009 \mathrm{H} 1 \mathrm{~N} 1$ influenza in the United States, April-June 2009.N Engl J Med. 2009 Nov 12;361(20):193544.

3. Ong AK, Chen MI, Lin L, Tan AS, Nwe NW, Barkham T, Tay SY et al., Improving the clinical diagnosis of influenza--a comparative analysis of new influenza A (H1N1) cases. PLoS One. 2009 Dec 29;4(12): 8453.

4. Duque V, Cordeiro E, Mota V, Vaz J, Morais C, Rodrigues F et al., The early days of pandemic (H1N1) 2009 virus infection in the central region of Portugal. Rev Port Pneumol. 2010 Nov;16(6):870-9.

5. Chan W L, Goh H K, Vasu A, Lim B L, Seow E. Experience of a screening centre for influenza $\mathrm{A} / \mathrm{H} 1 \mathrm{~N} 1$ : the first 50 days. Emerg Med J 2011;28:18-24.

6. Zarogoulidis P,Constantinidis T, Steiropoulos P,Papanas N,Zarogoulidis K, Maltezos E. Are there any differences in clinical and laboratory findings on admission between $\mathrm{H} 1 \mathrm{~N} 1$ positive and negative patients with flu-like symptoms. BMC Research Notes 2011, 4:4.

7. Chudasama RK, Patel UV, Verma PB, Amin CD, Savaria D, Ninama R et al., Clinico-epidemiological features of the hospitalized patients with 2009 pandemic influenza A (H1N1) virus infection in Saurashtra region, India (September, 2009 to February, 2010). Lung India. 2011 Jan-Mar; 28(1): 11-6.

8. Unal S, Gokce M, Aytac-Elmas S, Karabulut E, Altan I, OakayaParla K, Kara A et al. The Turkish Journal of Pediatrics 2010;52:5705 .

9. Centers for Disease Control and Prevention (CDC). Hospitalized patients with novel influenza A (H1N1) virus infection - California, April-May, 2009. MMWR Morb Mortal Wkly Rep. 2009 May 22;58(19):536-41.

10. Skarbinski J, Jain S, Bramley A, Lee EJ, Huang J, Kirschke D et al., Hospitalized patients with 2009 pandemic influenza A (H1N1) virus infection in the United States--September-October 2009. Clin Infect Dis. 2011 Jan 1;52 Suppl 1:50-9.

Copyright: (C) the author(s), 2019. It is an open-access article distributed under the terms of the Creative Commons Attribution License (CC BY 4.0), which permits authors to retain ownership of the copyright for their content, and allow anyone to download, reuse, reprint, modify, distribute and/or copy the content as long as the original authors and source are cited.

How to cite this article: Jutur S, Naik TKK. Mortality in Swine Flu: Descriptive Study. Asian J. Med. Res. 2019;8(1):ME14-ME16. DOI: dx.doi.org/10.21276/ajmr.2019.8.1.ME5 